\title{
Organik Buğday Tarımı Ülkemizde Hangi Koşullarda Daha Uygun Alternatif Olabilir
}

\author{
Aydın AKKAYA ${ }^{\mathscr{P}}$ (D) \\ ${ }^{1}$ Kahramanmaraş Sütçü İmam Üniversitesi, Ziraat Fakültesi, Tarla Bitkileri Bölümü, Kahramanmaraş, Türkiye \\ $\square:$ aakkaya@ksu.edu.tr
}

\section{ÖZET}

Ülkemizde organik buğdayın, toplam buğday ekim alanı ve üretim miktarı içerisindeki payı çok düşüktür. Geleneksel üretimden organik üretime geçişin önündeki en büyük engellerden birisi, organik buğdaydaki verim düşüklüğüdür. Ancak, geleneksel buğday yetiştiriciliğinde elde edilen verim azaldıkça, organik buğdayla geleneksel buğday verimi arasındaki fark azalmaktadır. Ülkemizde buğday üreticilerinin çoğu, küçük ölçekli arazilere sahip olduklarından ve az girdi kullandıklarından, geleneksel üretimde çok düşük verimler almaktadır. Ayrıca, buğday/girdi paritesi yıldan yıla giderek küçülmekte ve geleneksel buğdayda üretim maliyetleri giderek artmaktadır. Diğer yandan, geleneksel toprak işleme toprak organik maddesi üzerinde olumsuz etkiye sahip olduğundan, azaltılmış toprak işleme ve sıfır sürüm gibi toprak veremliliğini koruyan sistemlerin uygulanması gerekmektedir. Tarımsal kimyasalların kullanılmadığı süreçte seçilmiş olan yerel buğday genotiplerimiz, organik tarıma uygunluk bakımından çok önemli genetik kaynak durumundadır. Bu bilgilere dayanarak; Türkiye ortalamasının çok altında buğday verimi alınan ekolojilerde, küçük ölçekli ve az girdi kullanılan işletmelerde, sıfır sürüm uygulanarak toprak kalitesinin iyileştirilmesi hedeflenen arazilerde ve yerel çeşit yetiştiriciliğinin tercih edildiği durumlarda, organik buğday tarımının alternatif olabileceğini söylemek mümkündür.
DOI : 10.18016/ksudobil.286699

\section{Makale Tarihçesi}

Received : 20.01.2017

Accepted : 27.04.2017

Anahtar Kelimeler
Buğday,
organik tarım,
geleneksel tarım,
yerel koşullar,
yerel çeşitler

\section{Derleme Makale}

\section{Under Which Conditions of Turkey Organic Wheat Farming Could Be Better Alternative}

\section{ABSTRACT}

The organic wheat production has very small amounts in total wheat acreage and production of Turkey. The low yield in organic wheat is one of the biggest challenges in transition from conventional farming into organic farming. However, the yield gap between conventional and organic wheat decreases, as the yield of the conventional wheat decreases. The many wheat farmers in Turkey obtain very low yields, since they have small-scale farms and use low inputs. In addition, the wheat/input parities decrease year by year, while cost of conventional wheat production progressively increases. On the other hand, the conservative tillage systems such as minimum tillage and no-till should be applied because of the negative effects of the conventional tillage on the soils organic matter content. The local wheat landraces selected in the long term without agricultural chemicals are very important resources for organic farming. Therefore, it is suggested that the organic wheat farming could be better alternative to conventional wheat farming in the ecologies with lower yields than the average yield of Turkey, in farms with the small-scale and using low-input, in the lands to be improved soil quality by no-till application and in cases to be preferred the growth of local landraces.

\section{Article History \\ Geliş : 20.01.2017 \\ Kabul : 27.04.2017}

\author{
Keywords \\ Wheat, \\ organic farming, \\ conventional farming, \\ local conditions, \\ landrace
}

\section{Reviev Article}




\section{GİRIŞ}

Dünyada, son 15 yılda organik tarım giderek artış göstermiştir (Ponti ve ark., 2012). Ülkemizde organik tarımla ilgili faaliyetler 2004 yılında bir kanuna bağlanmış olup, Avrupa Birliği mevzuatına uyumlu bir halde kontrollü ve sertifikalı bir şekilde yürütülmektedir (Bayaner, 2010). Türkiye'nin organik tarım yönünden uygun koşullara sahip olduğu, organik tarımın istihdamı artıracağı, kırsal kalkınmaya katkı sağlayacağı öngörülmektedir (Gülçubuk, 2010). Ülkemizde 2005 yllında organik tarımla uğraşan yetiştirici sayısı 14401, organik tarım yapılan arazi genişliği 203811 hektar (doğal toplama alanları dahil), organik bitkisel üretim miktarı 421934 ton iken, 2015 yılında bu rakamlar sirasiyla 69967 kişi, 515268 hektar ve 1829291 tona çıkmıştır (Anonim, 2017). Görüldüğü gibi 2005 yllından 2015 yılına kadar geçen 10 yıllık süreçte, organik tarımla uğraşan yetiştirici sayısı, üretim alanı ve üretim miktarı önemli artışlar göstermiştir.

Geleneksel tarımda kullanılan ticari gübreler, pestisitler ve herbisitler gibi tarımsal kimyasalların, çevre ve insan sağlığı üzerindeki olumsuz etkileri görüldükçe, organik tarıma olan ilgi giderek artmaktadır. Tüketiciler, organik tarımdan elde edilen ürünlerin daha sağlıklı olduğunu düşünmekte, bilim adamları ise konuyu çeşitli yönleriyle araştırmaktadır. Örneğin, geleneksel ekmek yapımına göre organik ekmek üretiminin, daha az CO2 salınımı ve küresel ısınmaya neden olduğu, ancak organik buğdayın üretim merkezinden $420 \mathrm{~km}$ taşınması halinde farkın ortadan kalktığ 2009). Organik tarımda bitkilerin yenilir kısımlarında nitrat birikiminin az olduğu (Herencia ve ark., 2011), deney farelerinin organik buğdayı tercih ettiği (Velimirov ve ark., 2011), organik tarımın çevre üzerinde olumlu etkiye sahip olduğu (Tuomisto ve ark., 2012), toprak mikrobiyal biyomasını, organik karbonu ve fulvik asit fraksiyonunu yükselttiği (Santos ve ark., 2012), toprakta solucan türlerini artırdığı (Flohre ve ark., 2011), toprağın organik madde içeriğini (Marriott ve Wander, 2006), toprak verimliliğini ve biyoçeşitliliği (Mader ve ark., 2002; Hole ve ark., 2005) iyileştirdiği bildirilmektedir.

Organik buğday tarımının geleneksel buğday tarımına alternatif olup olamayacağı konusunda çeşitli tartışmalar yapılmaktadır. Giderek artan dünya nüfusunun ihtiyacını karşılayabilecek miktarda buğday üretiminin, organik tarımla gerçekleştirilip gerçekleştirilemeyeceği, tartışmaların odak noktasını oluşturmaktadır. Organik tarım çeşitli yönlerden üstünlüklere sahip olmakla beraber, ülkemizin toplam buğday ekim alanı ve üretim miktarı içerisinde, organik buğday henüz çok düşük paya sahiptir. Geleneksel üretimden organik üretime geçişin önünde çeşitli zorluklar bulunmasına rağmen, ülkemiz insanının temel besin kaynağı olan buğdayda organik üretim, üzerinde durulması gereken önemli bir konudur. Bu makalede, ülkemizin tarımsal yapısı ve araştırma sonuçları dikkate alınarak, organik buğday tarımının geleneksel buğday tarımına hangi koşullarda alternatif olabileceği konusunda öneriler getirilmeye çalışılmıştır.

\section{Verim Farkı}

Organik buğday tarımında verimin genel olarak düşük olması, geleneksek buğday tarımına karşı organik buğday tarımının en zayıf tarafinı oluşturmaktadır. Organik buğday tarımının yaygınlaşması halinde düşük verim nedeniyle, üretim-tüketim dengesinin bozulacağından, artan nüfusun ihtiyacinın karşılanamayacağından endişe duyulmaktadır. Orta Avrupa'da 21 yıllık bir araştırmada, organik tarım yapıldığında tane veriminde \% 20 oranında bir azalma olduğu belirlenmiştir (Mader ve ark., 2002). Dünyanın çeşitli ülkelerinden, deneme alanlarından ve yetiştirici tarlalarından toplanan 66 bilgi setine dayalı bir çalışma, organik buğday tarımında verimin ortalama \% 27 azaldığını, geleneksel tarımda verim azaldıkça (aradaki ilişki zayıf olmakla beraber) organik tarımla aradaki verim farkının azaldığını, yetiştirme teknikleri ve iklim koşulları gibi çeşitli faktörlere bağlı olarak verim farkı sınırlarının değiştiğini ortaya koymuştur (Ponti ve ark., 2012). Dünya genelindeki bu bulgulara benzer şekilde, Konya koşullarında yapılan bir araştırmada da geleneksel tarıma göre organik tarımda tane veriminin yaklaşık \% 30 kadar azaldığı belirlenmiştir (Aydın ve ark., 2010).

Türkiye ortalaması olarak 2015 yılı rakamlarına göre, geleneksel buğday tarımında tane verimi, makarnalık buğdaylarda kuru koşullarda $247 \mathrm{~kg} / \mathrm{da}$, sulu koşullarda $466 \mathrm{~kg} / \mathrm{da}$, ekmeklik buğdaylarda kuru koşullarda $244 \mathrm{~kg} / \mathrm{da}$, sulu koşullarda $412 \mathrm{~kg} / \mathrm{da}$ 'dır (Anonim, 2017). Ülkemizde bir çok marjinal alanda ve küçük ölçekli işletmelerde buğday tarımı yapılmaktadır. Bu duruma düşük girdi kullanımı da eklenince, ortalama buğday verimi bazı yörelerde Türkiye ortalamasının çok altına düşmektedir. Örneğin Erzurum'da il ortalaması olarak buğday verimi kuru koşullarda $135 \mathrm{~kg} / \mathrm{da}$, sulu koşullarda 232 kg/da, Tekman ilçesinde 95 kg/da, Karayazı ilçesinde kuru koşullarda $91 \mathrm{~kg} / \mathrm{da}$, sulu koşullarda 170 kg/da'dır. Konya'da il ortalaması olarak verim makarnalık buğdaylarda kuru koşullarda $286 \mathrm{~kg} / \mathrm{da}$, sulu koşullarda $496 \mathrm{~kg} / \mathrm{da}$, ekmeklik buğdaylarda kuru koşullarda 261 kg/da, sulu koşullarda 535 kg/da'dır. Buna karşılık ekmeklik buğdayda verim Sarayönü ilçesinde 127 kg/da'a, Taşkent ilçesinde 83 kg/da'a kadar düşmektedir. Şanlıurfa ilinde makarnalık buğdayda verim ortalaması suluda $485 \mathrm{~kg} / \mathrm{da}$ iken, kuruda 181 kg/da, Ceylanpınar'da 164 kg/da'a kadar inmektedir (Anonim, 2017).

Yukarıda örnek olarak verilen rakamlardan açıkça görüldüğü gibi, ülkemizin bazı yörelerinde buğday 
verimi Türkiye ortalamasının yarısı kadar, hatta yarısından da azdır. Bu kadar düşük düzeyde verim alınan yörelerde, iklim ve toprak özelliklerine bağlı sınırlamalar yanında, ekonomik koşullara bağlı az girdi kullanımı söz konusudur. Bu nedenle, geleneksel buğday yetiştiriciliği yapıldığı halde Türkiye ortalamasının çok altında verim alınan koşullarda, organik buğday yetiştiriciliği, geleneksel buğday yetiştiriciliğine alternatif olabilir. Geleneksel buğday tarımında elde edilen verim azaldıkça, organik tarımla aradaki verim farkı azaldığından (Ponti ve ark., 2012), bu yörelerde, organik buğday yetiştiriciliğine geçilmesi halinde verim yönünden önemli bir kayıp olmayacağı gibi, organik tarımın getireceği çeşitli yararlar da söz konusu olacaktır.

\section{Buğday/Girdi Fiyatları}

Buğday üretiminde kullanılan girdilerin çeşidi, miktarı ve fiyatları geçmişe göre çok değişmiş ve artmıştır. Bir zamanlar fazla girdiye ihtiyaç duymadan, elindeki mevcut olanaklarla üretim yapabilen ve kendi kendine yeterli olabilen buğday yetiştiricisi, günümüzde çok farklı girdilere bağımlı hale gelmiştir. Modern tarım alet ve makineleri, yeni ıslah edilen yüksek verim potansiyeline sahip çeşitlere ait sertifikalı tohumluk, ticari gübre ve ilaçlar gibi tarım kimyasalları, akaryakıt ve enerji, günümüzde tarımın temel girdileri haline gelmiştir. Günümüz buğday üreticileri kar etmek bir yana, tarımsal üretimlerine devam edebilmek için bu temel girdileri karşılayabilme mücadelesi vermektedir. Konunun daha iyi açıklanabilmesi yönünden, buğday fiyatı/girdi fiyatı oranlarının (paritelerin) birkaç tanesinin verilmesi yararlı olur. Örneğin, buğday/amonyum nitrat, buğday/üre, buğday/(20-20-0) ve buğday/motorin fiyat paritelerinin 2002 yılı değerleri 100 olarak alındığında, 2014 yılında bu fiyat pariteleri sirasiyla 65, 68, 80 ve 75'e gerilemiştir (Anonim, 2015 ve 2017). Bu rakamlardan da görüldüğü gibi, buğday fiyatları girdi fiyatlarının gerisinde kalmakta, buğday üreticileri ekonomik yönden giderek zayıflamaktadır. Buğday/girdi fiyat paritesi yönünden buğday yetiştiricisi aleyhine olan bu durum, çeşitli tarımsal desteklerle hafifletilmeye çalışılmakla beraber, girdi fiyatlarındaki yıllık artış miktarının, buğday fiyatlarındaki yıllık artış miktarından fazla olması, giderek buğday üreticisi aleyhine bir durum yaratmaktadir.

Türkiye'de buğday fiyatı, 1998-2004 dönem ortalaması olarak, ABD buğday fiyatından \% 40, Fransa buğday fiyatından \% 62 oranında fazla olmuş, fiyat yüksekliği yüksek maliyetten, maliyet yüksekliği ise yüksek girdi fiyatlarından kaynaklanmıştır (Anonim, 2005). ABD'ye kıyasla, Türkiye'de buğday üreticileri tohumluk için \% 409, gübre için \% 35, ilaçlama için \% 48, akaryakıt için ise \% 513 daha fazla masraf yapmakta, ABD'de buğday üreticisi maliyete kıyasla \% 31 kar ederken, Türkiye'de buğdaydan sağlanan gelir masrafların \% 3 gerisinde kalmakta ve yetiştiriciler zarar etmektedir (Anonim, 2005). Tarımsal ilaçlar ve ticari gübreler, geleneksel buğday üretiminin en önemli girdileri arasında yer almaktadır. Ülke genelinde, toplam masrafların \% 18'ni gübre, \% 7'sini ilaç harcamaları (Anonim, 2005), Konya'da değişen masrafların \% 16'sını ilaç ve gübre (Arısoy ve Oğuz, 2005), Yozgat ve Tokat'ta kuru koşullarda toplam harcamanın \% 22-23'nü ilaç (sadece herbisit olarak) ve gübre harcamaları oluşturmaktadır (Altıntaş, 2014).

Ülkemizde tarımsal işletmelerin yaklaşık \% 79'u, 100 dekardan küçük işletme büyüklüğüne sahip olup, 2049 dekar arazi grubuna sahip işletme oranı \% 33 kadardır (Anonim, 2008). Buğday yetiştiriciliğinde işletme büyüklüğü Avrupa Birliği’nde ortalama 174 dekar iken, ülkemizde 61 dekardır (Anonim, 2005). Küçük işletmelerde tarım yapan buğday çiftçisi, artan girdi fiyatlarından daha çok etkilenmekte, ekonomik yönden giderek daha çok zayıflamaktadır. Ülkemizde, bu tip işletmelerde geleneksel buğday yetiştiriciliği yerine, organik buğday yetiştiriciliği yapılması halinde, verimde bir miktar kayıp meydana gelse bile, girdilerin azalması, maliyetin düşmesi, ürünün yüksek fiyatla satılması gibi faktörlere bağlı olarak, ekonomik yönden yetiştiriciler daha fazla kazanç sağlayabilir. Nitekim organik buğday yetiştiriciliğinde, verimde yaklaşık \% 20 bir azalma söz konusu olsa bile, gübre ve enerji girdilerinde \% 34-54, ilaç kullanımında ise \% 97'ye varan azalmaların olduğu belirtilmektedir (Mader ve ark., 2002).

\section{Sifır Sürüm Koşulları}

Geleneksel buğday tarımında organik kökenli olmayan gübreler, bitki besleme ve gübreleme yönünden büyük kolaylık sağlamakta ve yetiştiriciler tarafindan yoğun bir şekilde kullanılmaktadır. Organik buğday tarımında ise bitki besleme ve gübreleme konusunda zorluklar bulunmakta olup, bu zorlukları aşmanın ön koşulu sürdürülebilir toprak kalitesi ve verimliliğidir. Toprak organik maddesi, sürdürülebilir toprak kalitesi ve verimliliği üzerinde doğrudan ve dolaylı birçok etkiye sahip olup, anahtar özellik niteliğindedir. Fakir topraklarda organik maddenin artırılması agregatlaşmayı sağlayarak toprak yapısını iyileştirir, erozyonu azaltır, infiltrasyonu ve toprağın su tutma kapasitesini artırır, bitki besin elementlerini depolar, toprak faunası için enerji sağlar, kirleticileri parçalar, topraktaki biyolojik çeşitliliği artırır, toprağın kolay tava gelmesini sağlar, tarımsal üretimde verim ve kaliteyi artırır (Cooperband, 2002; Lal, 2007).

Ülkemizde buğday tarımı yapılan toprakların \% 70’i organik madde yönünden fakir olup, \% 90'nı ise tarla tarımı yönünden istenilen \% 3'lük oranın altında organik maddeye sahiptir (Ülgen ve Yurtsever, 1974; Eyüboğlu ve ark., 1993). Yıllardan beri süregelen erozyon, anız yakma, kara nadas ve pullukla toprak işleme gibi uygulamalar, buğday tarımı yapılan toprakları organik madde içeriği yönünden fakir 
konuma düşürmüştür. Fakir topraklar yeterince su tutamadığından çok kısa süreyle tavda kalabilmekte veya hiç tava gelmemekte, toprak hazırlığı ve ekim gibi mutlaka tavda yapılması gereken işlemler için toprak tavı yakalanamamaktadır. Buna bağlı olarak sağlıklı çimlenme ve çıkış olmamakta, büyüme ve gelişme döneminde düşen yağişlardan ve topraktaki mevcut besin elementlerinden bitkiler yeterince yararlanamamaktadır. Toprağın pullukla işlenmesi, toprak işleme sıklığının artması ve bitki artıklarının toprağa geri verilmemesi durumunda, toprak organik maddesi önemli miktarda azaltmaktadır (Akkaya, 2008). Bu nedenle, günümüzde üretim sistemlerinde değişiklik yapılmakta, toprak ıslahı ve nem etkinliği yönünden önemli yararlar sağlayan, toprak verimliliğini artıran azaltılmış toprak işleme ve sıfır sürüm uygulamaları giderek yaygınlaşmaktadır (Anderson, 2005).

Akaryakıt, diğer tarla bitkilerinde olduğu gibi buğday yetiştiriciliğinde de ekimden hasada kadar bütün aşamalarda ihtiyaç duyulan en önemli girdi durumundadır. Buğday tarımında tüketilen toplam 14 litrelik motorinin \% 21’i birinci sürüm için kullanılmaktadır (Anonim, 2005). İkileme ve üçleme yapılması halinde, toprak hazırlığı için kullanılan akaryakıt tüketimi daha da artmakta, toplam maliyet içerisindeki payı \% 20'yi geçmektedir (Altıntaş, 2014). Öte yandan, geleneksel toprak hazırlığına kıyasla doğrudan ekimde enerji etkinliğinin 2 kat arttığ belirtilmektedir (Serpi ve ark, 2011).

Pullukla toprak işlemenin toprak kalitesi ve çevre üzerindeki olumsuz etkileri, toprak hazırlığında fazla akaryakıt tüketilmesi, yüksek akaryakıt fiyatları gibi faktörler yanında topraklarımızın organik madde yönünden fakir oluşu, sıfir sürüm ve azaltılmış toprak işlemeye geçişi gerektiren önemli etkenlerdir. Bu nedenle, toprak verimliliğinin artırılmasının hedeflendiği koşullarda, azaltılmış toprak işleme veya sıfır sürümle birlikte organik buğday yetiştiriciliği yapılması daha doğru ve yararlı bir tercih olabilir.

\section{Yerel Çeşit Tercihi}

Yüksek girdili geleneksel yetiştiricilik koşullarında seçilmiş yeni ıslah çeşitleri, organik tarım koşullarına yeterince uyum sağlayamamaktadır (Murphy ve ark., 2007; Wolfe ve ark., 2008). Düşük verimli koşullarda, eski buğday genotiplerinin yeni genotiplerden daha fazla N kullanabildikleri (Foulkes ve ark., 1998) ve mikorhizal ilişkiler konusunda daha aktif olabildikleri (Hetrick ve ark., 1993) belirtilmektedir. Organik tarıma uygun genotiplerin geliştirilmesinde, genel adaptasyon yeteneğine dayalı seleksiyonlar yerine, özel adaptasyon yeteneğine sahip genotiplerin seçilmesi, yöresel adaptasyonun esas alınması önerilmektedir (Banziger ve Cooper, 2001; Ghaouti ve Link, 2009). Organik buğday tarımında yabancı ot tür ve yoğunluğu artabilmekte (Gosme ve ark., 2012), yabancı ot yoğunluğuna bağlı olarak verim \% 40 kadar azalabilmekte (Mason ve ark., 2007), yabancı otlarla rekabet yeteneği yönünden buğday genotipleri arasında önemli farklar bulunmaktadır (Hoad ve ark., 2008). Son 150 yıllık süreçte, buğday veriminde önemli artış sağlanmış, ancak yabancı otlarla rekabet yönünden yeni çeşitlerde az da olsa bir gerileme söz konusu olmuştur (Murphy ve ark., 2008a). Uzun boylu, erken gelişmesi hızlı ve fazla kardeşlenen genotiplerin yabancı otlara karşı daha fazla rekabet üstünlüğüne sahip olduğu bildirilmektedir (Mason ve ark., 2007). Ayrıca, buğday çok sayıda allelopatik bileşikler içermekte olup, allelopatik ilişki yönünden genotipler arasında önemli farklar bulunmaktadır (Lammerts van Bueren ve ark., 2011). Geleneksel tarımda olduğu gibi, organik tarımda da hastalık ve zararlılarla mücadelede, dayanıklı çeşit geliştirmek büyük önem arz etmekte olup, organik tarımda sorun olan hastalıklara karşı dayanıklı çeşit geliş̧irmede, uzun boylu eski çeşitlerden yararlanılmaktadır (Murphy ve ark., 2007; Lammerts van Bueren ve ark., 2011). Diğer önemli bir husus ise son 120 ylllık süreçte buğday veriminde önemli artış sağlanmış olmasına rağmen, kalsiyum dışında tanenin bakır, demir, magnezyum, manganez, fosfor, selenyum ve çinko içeriklerinin yeni çeşitlerde azalmış olması, aksine eski çeşitlerde bu elementlerin beslenme açısından ihtiyaç duyulan miktarlarda bulunmasıdır (Murphy ve ark., 2008b).

Özet olarak, organik buğday tarımına uygunluk yönünden; yörelere özgü adaptasyon, yabancı otlarla rekabet için uzun boylu olma ve fazla kardeşlenme, allelopatik ve mikorhizal özellikler, hastalık ve zararlılara dayanıklılık, yüksek azot ve su kullanım etkinliği, dengeli besin elementi içeriğine sahip olma gibi özellikler aranmaktadır. Yerel buğday kaynaklarımızın bu ihtiyaçları karşılama potansiyeli çok yüksektir. Çünkü yerel buğdaylarımız, tarımsal kimyasal kullanımının söz konusu olmadığı binlerce yıllık süreçte, organik tarım yapılan koşullarda seçilmiştir. Ayrıca tüketiciler arasında, asırlardan beri oluşan alışkanlıklara bağlı olarak, yerel buğday çeşitlerinden elde edilen ürünler aranır durumdadır. $\mathrm{Bu}$ nedenle, üretici ve tüketici tercihleri veya diğer nedenlere bağlı olarak, yerel buğday çeşitlerinin ekim ve üretiminin tercih edildiği koşullarda, organik buğday yetiştiriciliği, geleneksel buğday yetiştiriciliğine alternatif olabilir.

\section{SONUÇ}

$\mathrm{Bu}$ makalede açıklanmaya çalışılan ana fikirler aşağıdaki gibi sıralanabilir.

- Geleneksek buğday yetiştiriciliğinde verim azaldıkça, organik buğdayla geleneksel buğday arasındaki verim farkı da azalmaktadır.

- Ülkemizde bazı yörelerde buğday yetiştiricileri çok düşük verimler almaktadır.

- Ülkemizde geleneksel buğdayda üretim maliyetleri giderek artmaktadır.

- Organik madde içeriği düşük olan 
topraklarımızda, geleneksel toprak işleme sürdürülebilir toprak kalitesini tehdit etmektedir.

- Yerel genotiplerimiz, organik tarıma uygunluk bakımından önemli bir kaynaktır.

Bu temel bilgiler esas alınarak; Türkiye ortalamasının çok altında buğday verimi alınan ekolojilerde, küçük ölçekli ve az girdi kullanan işletmelerde, sıfır sürüm uygulanarak toprak kalitesi iyileştirilmesi gereken arazilerde ve yerel çeşitlerin tercih edildiği durumlarda, geleneksel buğday tarımı yerine, organik buğday tarımı önerilebilir.

\section{KAYNAKLAR}

Akkaya A 2008. Tahılın Kalbi Konya'dan Çağrı. Ülkesel Tahıl Sempozyumu, 1-13, 2-5 Haziran, Konya.

Altıntaş G 2014. Tokat, Amasya, Yozgat ve Sivas yörelerinde yetiştirilen bazı tarım ürünlerinin 2013 yll üretim girdileri ve maliyetleri. Orta Karadeniz Geçit Kuşağı Tarımsal Araştırma İstasyonu Müdürlüğü, Enstitü Yayın, 261, 23, http://arastirma.tarim.gov.tr/tokatarastirma/Belge ler/Maliyetler/maliyetler_2013.pdf (Erişim tarihi 11.11.2015).

Anderson RL 2005. Are some crops synergistic to following crop. Agron. J., 97, 7-10.

Anonim 2005. Buğday Raporu. Türkiye Ziraat Odaları Birliği, Ankara.

Anonim 2008. Tarımsal İşletme Yapı Araştırması 2006. TC Başbakanlık Türkiye İstatistik Kurumu, Haber bülteni, 196.

Anonim 2015. Tarımsal Veriler. T.C. Gıda, Tarım Ve Hayvancılık Bak. Tarımsal Araştırmalar ve Politikalar Genel Müdürlüğü. Tarımsal Ekonomi ve Politika Geliştirme Enstitüsü, Ankara, http://www.tarim.gov.tr/Belgeler/SagMenuVeriler/ Tarimsal_Veriler.pdf (Erişim tarihi 11.11.2015).

Anonim 2017. Türkiye İstatistik Kurumu, http://www.tuik.gov.tr/Start.do (Erişim tarihi 12.01.2017).

Arısoy H, Oğuz C 2005. Tarımsal Araştırma Enstitüleri tarafindan yeni geliştirilen buğday çeşitlerinin tarım işletmelerinde kullanım düzeyi ve geleneksel çeşitler ile karşılaştırmalı ekonomik analizi-Konya İli Örneği, Ankara,

http://www.tepge.gov.tr/Dosyalar/Yayinlar/83c3938d2 e15467289823d9eb23a05b1.pdf (Erişim tarihi 3.11.2015).

Aydın M, Yılmaz M, Kara AÇ, Soylu S 2010. Ekmeklik buğdayda organik ve konvansiyonel yetiştiriciliğin karşılaştırması üzerine bir araştırma. Türkiye IV. Organik Tarım Sempozyumu, 102-106, 28 Haziran1 Temmuz 2010, Erzurum.

Banziger M, Cooper M 2001. Breeding for low input conditions and consequences for participatory plant breeding: Examples from tropical maize and wheat. Euphytica, 122, 503-519.
Bayaner A 2010. Tarım ve Köyişleri Bakanlığı'nın organik tarım faaliyetleri. Türkiye IV. Organik Tarım Sempozyumu, 31-36, 28 Haziran-1 Temmuz 2010, Erzurum.

Cooperband L 2002. Building soil organic matter with organic amendments. A resource for urban and rural gardeners, small farmers, turfgrass managers and large-scale producers. Univ. of WisconsinMadison, Center for Integrated Agricultural Systems.

Eyüboğlu F, Candaş İ, Örs G 1993. Konya ili topraklarının özellikleri ve gübre ihtiyacı. 1. Konya'da Hububat Tarımının Sorunları ve Çözüm Yolları Sempozyumu, 33-49, 12-14, Mayıs, Konya.

Flohre A, Rudnick M, Traser G, Tscharntke T, Eggers $\mathrm{T}$ 2011. Does soil biota benefit from organic farming in complex vs. simple landscapes?. Agriculture, Ecosystems and Environment, 141, 210-214.

Foulkes MJ, Sylvester B, Scott, RK 1998. Evidence for differences between winter wheat cultivars in acquisition of soil mineral nitrogen an uptake and utilization of applied fertilizer nitrogen. Journal of Agricultural Sci., 130, 29-44.

Ghaouti L, Link W 2009. Local vs. formal breeding and inbred line vs. synthetic cultivar for organic farming: Case of Vicia faba L. Field Crop Research, 110, 167-172.

Gosme M, Villemandy M, Bazot M, Jeuffroy MH 2012. Local and neighbourhood effects of organic and conventional wheat management on aphids, weeds, and foliar diseases. Agriculture, Ecosystems and Environment, 161, 121-129.

Gülçubuk B 2010. Kırsal kalkınma ve organik tarım. Türkiye IV Organik Tarım Sempozyumu, 25-30, 28 Haziran-1 Temmuz 2010, Erzurum.

Herencia JF, Garcia-Galavis PA, Dorado JAR, Maqueda C 2011. Comparison of nutritional quality of the crops grown in an organic and conventional fertilized soil. ScientiaHorticulturae, 129, 882-888.

Hetrick BAD, Wilson GWT, Cox TS 1993. Mycorrhizal dependence of modern wheat cultivars and ancestors-synthesis. Canadian journal of Botany, $71,512-518$.

Hoad S, Topp C, Davies K 2008. Selection of cereals for weed suppression in organic agriculture: a method based on cultivar sensitivity to weed growth. Euphytica, 163, 355-366.

Hole DG, Perkins A, Wilson JD, Alexander IH, Grice PV, Evans AD 2005. Does organic farming benefit biodiversity? Biological Conservation, 122, 113-130.

Lal R 2007. Farming carbon. Soil \& Tillage Research, $96,1-5$.

Lammerts van Bueren ET, Jones SS, Tamm L, Murphy KM, Myers JR, Leifert C, Messmer MM 2011. The need to breed crop varieties suitable for organic farming, using wheat, tomato and broccoli as examples: A review. NJAS-Wageningen Journal of Life Sciences, 58, 193-205. 
Mader P, Fliessbach A, Dubois D, Gunst L, Fried P, Niggli U 2002. Soil fertility and biodiversity in organic farming. Science, 296, 1694-1697.

Marriott EE, Wander M 2006. Qualitative and quantitative differences in particulate organic matter fractions in organic and conventional farming systems. Soil Biology \& Biochemistry, 38, 1527-1536.

Mason HE Navabi A, Frick BL, O'Donovan JT, Spaner DM 2007. The weed competitive ability of Canada Western Red Spring Wheat cultivars grown under organic management. Crop Sci., 47, 1167-1176.

Meisterling K, Samaras C, Schweizer V 2009. Decisions to reduce greenhouse gases from agriculture and product transport: LCA case study of organic and conventional wheat. Journal of Cleaner Production, 17, 222-230.

Murphy KM, Campbell KG, Lyon SR, Jones SS 2007. Evidence of varietal adaptation to organic farming systems. Field Crops Research, 102, 172-177.

Murphy KM, Dawson JC, Jones SS 2008a. Relationships among phenotypic growth traits, yield and weed suppression in spring wheat landraces and modern cultivars. Field Crops Research, 105, 107-115.

Murphy KM, Reeves PG, Jones SS 2008b. Relationship between yield and mineral nutrient concentrations in historical and modern spring wheat cultivars. Euphytica, 163, 381-390.
Ponti T, Rijk B, Ittersum MK 2012. The crop yield gap between organic and conventional agriculture. Agricultural Systems, 108, 1-9.

Santos VB, Araujo ASF, Leite LFC, Nunes LAPL, Melo WJ 2012. Soil microbial biomass and organic matter fractions during transition from conventional to organic farming systems. Geoderma, 170, 227-231.

Serpi Y, Topal A, Sade B, Ögüt H, Soylu S, Boyraz N, Bilgili N, Direk M 2011. Buğday Raporu. UHK, Ulusal Hububat Konseyi, 1.

Tuomisto HL, Hodge LD, Riordan P, Macdonald DW 2012. Does organic farming reduce environmental impacts?-A meta-analysis of European research. Journal of Environmental Management, 112, 309320.

Ülgen N, Yurtsever N 1974. Türkiye gübre ve gübreleme rehberi. Toprak ve Gübre Araştırma Enstitüsü Teknik Yayınlar Serisi, 28, Kemal Matbaası, Ankara.

Velimirov A, Lueck L, Shiel R, Plöger A, Leifert C 2011. Preference of laboratory rats for food based on wheat grown under organic versus conventional production conditions. NJAS - Wageningen Journal of Life Sci., 58 (3-4), 85.88.

Wolfe MS, Baresel JP, Desclaux D, Goldringer I, Hoad S, Kovacs G, Löschenberger F, Miedaner T, Ostergard H, Lammerts van Bueren ET 2008. Developments in breeding cereals for organic agriculture. Euphytica, 163, 323-346. 